\title{
Description of a remarkable new species of the genus Coleolissus from the Western Ghats (India), with notes on this and related genera (Coleoptera: Carabidae)
}

\author{
Описание примечательного нового вида рода Coleolissus \\ из Западных Гат (Индия) с замечаниями об этом и бцизких ему \\ родах (Coleoptera: Carabidae)
}

\author{
B.M. Kataev \\ Б.M. Катаев
}

Zoological Institute, Russian Academy of Sciences, Universitetskaya Emb. 1, St Petersburg 199034, Russia.

Зоологический институт, Российская Академия Наук, Университетская наб. 1, Санкт-Петербург 199034, Россия, harpal@zin.ru

KEY WORDS: Coleoptera, Carabidae, Harpalini, Selenophori group, Coleolissus, Hyphaereon, Calathomimus, Tenuistilus, Allosiopelus, Oriental region, India, new species, new synonym.

КЛЮЧЕВЫЕ СЛОВА: Coleoptera, Carabidae, Harpalini, Selenophori group, Coleolissus, Hyphaereon, Calathomimus, Tenuistilus, Allosiopelus, Ориентальная область, Индия, новый вид, новый синоним.

ABSTRACT. Coleolissus inessae sp.n. is described from the Western Ghats (Karnataka, India), which is markedly distinguished from all other congeners by elongate body with comparatively long pronotum not depressed latero-basally combined with shorter mandibles and one pair of marginal setae on last visible abdominal sternite of male. The relationships of the new species as well as the distinctive features and status of Coleolissus Bates, 1892, Hyphaereon MacLeay, 1825, Calathomimus Bates, 1886 and Allosiopelus Ito, 1995 are briefly discussed. The following new synonymy is proposed: Coleolissus Bates, 1892 = Tenuistilus Habu, 1978, syn.n.

РЕЗЮМЕ. Описан новый вид Coleolissus inessae sp.n. из Западных Гат (Карнатака, Индия), который заметно отличается от других видов рода удлинённым телом с относительно более длинной переднеспинкой без латеро-базальных уплощений, а также более короткими мандибулами и наличием только одной пары краевых щетинок на последнем видимом стерните брюшка самца. Обсуждаются родственные связи нового вида, а также статус и диагностические признаки Coleolissus Bates, 1892, Hyphaereon MacLeay, 1825, Calathomimus Bates, 1886 и Allosiopelus Ito, 1995. Предложена новая синонимия: Coleolissus Bates, 1892 = Tenuistilus Habu, 1978, syn.n.

\section{Introduction}

The supraspecific taxa of the Selenophori genusgroup of the tribe Harpalini were revised by Noonan [1985a,b] on a worldwide basis. Within this genusgroup he recognized the Oxycentrus phyletic stock with two genera, Hyphaereon MacLeay, 1825 and Oxycentrus Chaudoir, 1854, which is characterized by mandibles slightly to considerably longer than in typical selenophorines. The genera Coleolissus Bates, 1892 and Calathomimus Bates, 1886 were treated by him as congeneric with the genus Hyphaereon. Among the distinctive features of the latter genus, Noonan [1985a: 54] listed the following: body form not subcylindrical; inner elytral intervals lacking pubescence; elytral interval 3 with row of setigerous punctures; mentum with median tooth; mandibles elongate and in repose both with apices projected beyond apex of labrum; clypeal apex not deeply emarginated medially and not exposing base of labrum; and frontal foveae not modified except for the clypeo-ocular prolongations present in some species. According to Noonan [1985a: 55], the distinctive characters of Coleolissus and Calathomimus are "not as stable as previously believed and do not warrant separate status". In that time, the genus Hyphaereon in such interpretation included 25 species distributed from Sri Lanka, India, Burma and Ryukyu Islands via the Indo-Malay Archipelago to New Guinea and northern Australia. However, Noonan's concept of the genus Hyphaereon was not accepted by subsequent authors. During the past three decades, 54 new species were described as members of separate genera: 15 species within the genus Hyphaereon [Ito, 1990, 1997a, 2004, 2007, 2008, 2016, 2017], four species within the genus Calathomimus [Ito, 1990, 1991b, 1995, 1997a], and 35

How to cite this article: Kataev B.M. 2021. Description of a remarkable new species of the genus Coleolissus from the Western Ghats (India), with notes on this and related genera (Coleoptera: Carabidae) // Russian Entomol. J. Vol.30. No.4. P.448-454. doi: 10.15298/rusentj.30.4.07 
species within the genus Coleolissus [Ito, 1987, 1991a, 1993, 1999, 2001, 2004, 2006, 2007, 2008, 2014, 2016, 2017; Ito, Wrase, 1998; Baehr, 2018; Ito, Liang, 2018]. In addition, two new species were described [Ito, 1995, 2016] within the newly described genus Allosiopelus Ito, 1995 having similar characteristics. Despite the previous wide concept of the genus Hyphaerion, in some cases the same names were used for species placed in different genera. Notice that none of these publications discussed Noonan's treatment of Hyphaerion, and none of them included the diagnoses of the genera (except for Allosiopelus) in which these new species were described. In fact Noonan's [1985a] revision was simply ignored. Moreover, some species originally described as Calathomimus were subsequently transferred to the genus Hyphaereon without any explanation [Ito in Kataev et al., 2003; Ito, 2004]. All this creates great difficulties for understanding the generic affiliation of certain species. The status of many species is also in doubt, since the type material of the previously described species was not examined when recognizing new taxa. Some of names of these new species will certainly fall in synonymy. Meanwhile the study of the literature and the available material, including the types of many species, has revealed that although Hyphaereon, Coleolissus and Calathomimus appear to be natural units, they were treated by almost all preceding authors inadequately.

In the present paper, a new species of the genus Coleolissus with unusual combination of characters is described from the Western Ghats (India), and distinctive features and status of this genus and also Hyphaereon, Calathomimus, Allosiopelus as well as Tenuistilus Habu, 1978, which was omitted by Noonan [1985a], are briefly discussed.

The following abbreviations are used for the depositories of the type specimens: MNHN — Muséum National d'Histoire Naturelle, Paris, France; ZIN — Zoological Institute of the Russian Academy of Sciences, Saint Petersburg, Russia.

Measurements were made under the stereomicroscope LOMO MBC 10 using an ocular-micrometer and were taken as follows: body length, measured from the anterior margin of the clypeus to the elytral apex; maximum width of head (HWmax), measured as the maximum linear distance across the head, including the eyes; minimum width of head (HWmin), measured as the minimum linear distance across the head, in this case corresponding to the neck constriction just behind the eyes; length of pronotum (PL), measured along its median line; length of elytra (EL), measured from the basal border in the scutellar region to the apex of the sutural angle; maximum width of pronotum (PWmax) and of elytra (EW), both measured at their broadest points; minimum widths of pronotum (PWmin-ap and PWminbas), measured between apical angles and at its narrowest points near the hind angles, respectively; length and width of metepisterna, measured along their inner and anterior margins, respectively. Male genitalia were examined in glycerin and then embedded in Euparal.
Drawings were prepared by using an ocular grid (10 $\mathrm{x} 10$ squares) attached to the abovementioned stereomicroscope. Habitus photograph was taken with a Canon EOS 6 D camera with a Canon MP-E $65 \mathrm{~mm}$ objective lens, and subsequently processed using the Helicon Focus 6 software and optimized with Photoshop ${ }^{\circledR}$ CS2 .

\section{Results}

\section{Coleolissus inessae Kataev, sp.n.} Figs 1-6.

MATERIAL. Holotype: $0^{7}$, "INDIA: W Karnataka, W Gats Mts, jog Falls, $530 \mathrm{~m}$, at light, $14^{\circ} 13.240^{\prime} \mathrm{N} 74^{\circ} 48.471^{\prime} \mathrm{E}, 2-5 . \mathrm{XI} .2013$ S. Saluk leg." (ZIN).

DESCRIPTION (male). Body elongate, medium-sized, length $7.8 \mathrm{~mm}$, width $3.0 \mathrm{~mm}$. Habitus as in Fig. 1.

Body pitch black, shiny and iridescent on dorsal and ventral sides, with labrum, base of mandibles and very narrow lateral margins of pronotum reddish brown; palpi, antennae and legs yellowish brown; antennomeres 3-11 and apices of tibiae very slightly infuscate.

Head medium-sized (HWmax/PWmax 0.68, HWmin/ PWmax 0.53), impunctate. Eyes large, moderately convex (HWmax/HWmin 1.28), separated ventrally from buccal fissure by very short distance about as wide as antennomere 1 basally. Genae glabrous. Tempora short, oblique, gently sloping to neck. Labrum slightly convex, very shallowly concave anteriorly. Clypeus somewhat flat, slightly emarginated along anterior margin, with a pair of lateral setigerous pores and a pair of very short longitudinal wrinkles each adjacent medially to lateral pore. Fronto-clypeal suture fine, slightly impressed, almost straight. Frontal foveae like elongate short pit without prolongation on clypeus. Fronto-ocular furrows very fine, vaguely reaching supraocular furrows. Frons with angulate shallow depression and with a few very fine micropunctures at lateral margins of this depression. Supraorbital furrows very narrow, touching upper margin of eyes. Supraorbital setigerous pores small, situated slightly before level of posterior margin of eyes and removed from supraorbital furrows by diameter of pores. Mentum separated from submentum by complete transverse suture (Fig. 2), with a very short and wide median tooth; epilobes markedly widened apically; submentum with one pair of long lateral setae. Ligular sclerite almost parallel-sided, truncate at apex, with one pair of ventroapical setae. Paraglossae glabrous, moderately wide, markedly longer than ligular sclerite and separated from it apically by narrow notches. Basal labial palpomere not carinate; penultimate labial palpomere about as long as ultimate one. Mandibles very moderately elongate, evenly curved apically, with wide bases; left mandible blunted at tip. Dorsal microsculpture very fine, obliterated, consisting of indistinct, more or less isodiametric meshes. Antennae slender, surpassing pronotal basal edge by two apical antennomeres, pubescent from apical half of antennomere 3, with antennomeres $4-8$ about two times as long as wide and basal antennomere slightly longer than antennomere 3 .

Pronotum transverse, comparatively long for genus (PWmax/PL 1.34), widest slightly before the middle, very moderately narrowed apically and basally (PWmax/PWminap 1.44, PWmax/PWmin-bas 1.20), with one lateral seta inserted at the end of the anterior third. Sides rounded along entire length; lateral bead complete, throughout very narrow. Apical margin shallowly emarginated, almost straight medi- 


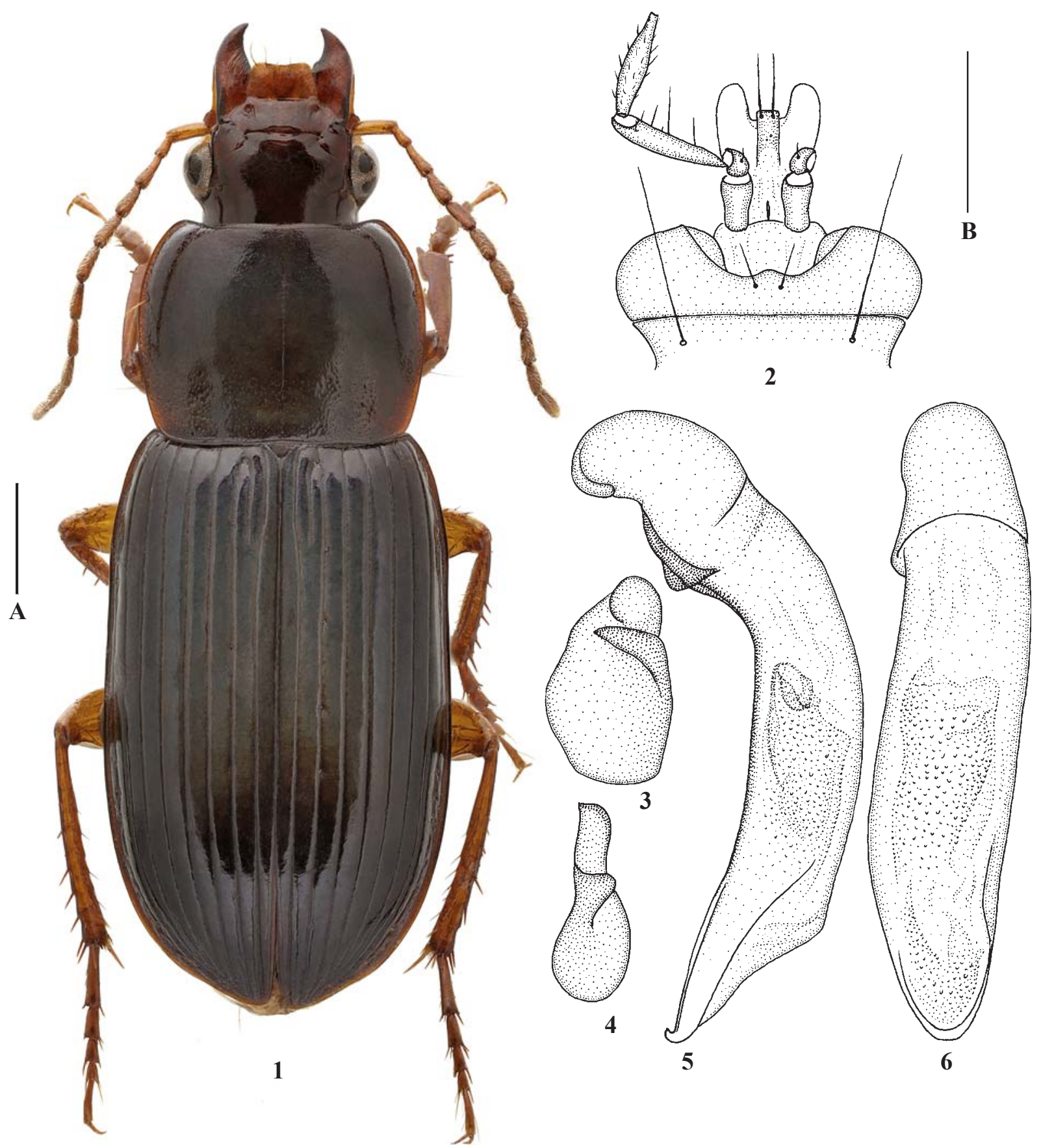

Figs 1-6. Coleolissus inessae sp.n. 1 - general view; 2 - labium; 3 - left paramere; 4 - right paramere; 5 - median lobe of aedeagus, lateral view; 6 -same, dorsal view. Scale bars: A = $1.0 \mathrm{~mm}(1), \mathrm{B}=0.5 \mathrm{~mm}(2-6)$.

Рис. 1-6. Coleolissus inessae sp.n. 1 - внешний вид; 2 - нижняя губа; 3 - левая парамера; 4 - правая парамера; 5-6 срединная лопасть эдеагуса (5 - сбоку; 6 - сверху). Масштаб: А = 1,0 мм (1); В =0,5 мм (2-6).

ally, very narrowly bordered along entire length; border slightly obliterated at the middle. Apical angles rounded, slightly protruding anteriorly. Basal margin almost straight in middle portion, slightly rounded laterally, bordered along entire length, not ciliate, slightly longer than apical margin (PWmin-bas/PWmin-ap 1.20) and almost as long as base of elytra between humeral angles. Basal angles obtuse, rounded at apex. Disc convex. Lateral depressions beginning from lateral setae, very shallow, widened basally and disappearing before the apical quarter. Basal foveae elongate oval, shal- low, isolated from lateral margins and from each other by convex areas. Median line distinct, slightly impressed, isolated from apical margin and touching basal margin. Anterior transverse depression wide and shallow. Surface with dense distinct non-setigerous punctures basally and along sides, with sparser and finer punctation at apical margin including anterior transverse depression. Microsculpture highly obliterated, not forming distinct meshes.

Elytra convex, elongate, only slightly wider than pronotum (EL/EW 1.64, EL/PL 2.61, EW/PWmax 1.19), widest 
before the apical third; sides very slightly diverging in the apical two thirds, with weak sinuation before the middle, and roundly converging in the apical third; subapical sinuation distinct but shallow. Humeri rounded, with an indistinct denticle recognizable in caudal view. Sutural angle narrowly rounded at tip, not extended posteriorly. Basal edge slightly arched, forming a sharp, very obtuse angle with lateral margin. Striae comparatively wide, impunctate, impressed along entire length, reaching anteriorly basal elytral border, with granulate microsculpture on bottom. Intervals glabrous, almost flat on disc, gradually becoming convex and narrow at apex; intervals 8 and 9 throughout and other intervals just at apex irregularly punctate; punctation of intervals 8 and 9 in apical half very fine and sparse. Parascutellar (abbreviate) striole long, about 0.2 as long as elytron, with a large setigerous pore basally isolated from basal elytral border. Interval 3 with a series of seven very distinct discal setigerous pores adjoining to stria 2 along its entire length; intervals 5 and 7 without discal pores. Marginal umbilicate series without distinct gap at middle, consisting of 22-25 setigerous pores. Lateral groove narrow and flat throughout, without distinct elongate convexity along this groove apically. Microsculpture highly obliterated on intervals, without distinct meshes or lines, granulate in lateral groove.

Wings fully developed.

Ventral side of thorax glabrous except for sparse very fine short setae on prosternum anteriorly, almost throughout finely punctate laterally. Metepisternum markedly longer than wide, strongly narrowed posteriorly.

Metacoxae each only with two obligatory setigerous pores, without additional pores and setae. Profemur with deep longitudinal excavation on inner side. Protibia on dorsal side without longitudinal sulcus, with two similar sized preapical spines on outer margin. Metafemur ventrally with two setae at posterior margin and without setae at anterior margin. Proand mesotarsi dorsally with a few very fine and short setae. Protarsomeres 1-4 and mesotarsomeres 2-4 (in male) markedly widened, short, with biseriate adhesive scales ventrally; mesotarsomere 1 not widened, elongate, only slightly shorter than mesotarsomeres 2 and 3 combined, with a pair of very small scales just at apex. Metatarsus slender, about as long as HWmax, with tarsomeres 2 and 3 weakly and tarsomeres 3 and 4 markedly widened distally; metatarsomere 1 slightly longer than metatarsomeres 2 and 3 combined. Tarsomere 5 with two pairs of ventro-lateral setae.

Abdominal sternites mostly smooth, only two basal ones with very fine non-setigerous punctures; last visible sternite (VII) (in male) very widely rounded at apex, with one pair of marginal setae; these setae not removed from margin.

Aedeagus (Figs 3-6) with comparatively large parameres (Figs 3, 4) and basal bulb. Median lobe of aedeagus in lateral view (Fig. 5) arcuate on dorsal side, with ventral margin almost straight in middle portion and convex in the apical quarter; apex sharply hooged ventrally; in dorsal view median lobe (Fig. 6) almost straight, with terminal lamella very wide and short, rounded apically. Apical orifice in dorsal position, wide apically. Internal sac with spiny formation medially, without spines.

ETYMOLOGY. Named after Prof. Inessa Kh. Sharova (1931-2021), the famous entomologist and soil zoologist, the teacher of many carabidologists in the former Soviet Union and Russia, to whose memory this volume is dedicated.

COMPARISON. This new species is markedly distinguished from all other congeners by elongate body with comparatively long pronotum which is not depressed laterobasally. In addition, unlike most of other species, its mandi- bles are shorter and abdominal sternite VII (in male) is with only one pair of marginal setae.

DISTRIBUTION. Known from the Western Ghats near Jog Falls, Western Karnataka, India.

REMARKS. This new species is rather dissimilar to any other described species and at first I hesitated to place it in any described genus. Such characters as the distinct frontoocular furrows, glabrous paraglossae, several setae on penultimate labial palpomere, elytral interval 3 with row of setigerous pores, long metatarsomere 1 and pro- and mesotarsi of male with biseriate adhesive scales are clearly indicate that it is a member of the Selenophori group. In having moderately elongate mandibles and glabrous, almost subcylindrical body without latero-basal depressions on pronotum, it looks as somewhat intermediate form between Coleolissus and Oxycentrus. Although these taxa are always regarded as separate genera, the structural differences between them are not evident [Kataev, 2006] and assignment of some species to one or another genus is difficult since the body form is rather variable in the both genera. For example, two apparently closely related species with elongate body were described by one author [Ito, 1997b, 1999] as Oxycentrus (s. str.) subarcuaticollis Ito, 1997 and Coleolissus (Tenuistilus) iridipennis Ito, 1999 without comparing them, and their generic affiliation remains unclear. They both markedly differ from $C$. inessae sp.n. at least in body size larger (about $9.5-12.0 \mathrm{~mm}$ ) and in having pronotum markedly depressed latero-basally, with more rounded sides and basal angles, and abdominal sternite VII of male with two pairs of marginal setae. The new species is included in the genus Coleolissus on the basis of the following characters: frontal foveae without prolongation on clypeus, parascutellar striole long, interval 3 with a row of seven setigerous pores, and protibia with two preapical spines on outer margin. Each of these characters occurs in Oxycentrus but not in such combination. As opposed to Coleolissus, most species of Oxycentrus have frontal foveae with more or less distinct prolongation on clypeus, parascutellar striole short or absent, interval 3 with less number of setigerous pores (in some species these pores absent), and protibia with more than two preapical spines on outer margin. The very moderately elongate mandibles of $C$. inessae sp.n., shorter than in most Coleolissus and Oxycentrus, and its comparatively long pronotum without latero-basal depressions, which are present probably in all congeners, suggest that this species is rather isolated within Coleolissus. The similarity to Oxycentrus may be convergent (most species of Coleolissus and Oxycentrus have the plesiomorphic state of the abdominal sternite VII with two pairs of marginal setae as opposed to the apomorphic state in the new species with only one, inner, pair of setae), but it is not improbably that $C$. inessae sp.n. is phylogenetically close to the branching node of two phyletic lineages sensu Noonan [1985b]: the less modified lineage Hyphaereon and the more specialized lineage Oxycentrus. The relationships and status of $C$. inessae sp.n. need further study. Interestingly, the new species is somewhat similar in appearance to some species of Siopelus Murray, 1859 having smooth elytra, but well distinguished from them by having longer mandibles and glabrous genae and outer elytral intervals. The predominantly Ethiopian genus Siopelus seems to occupy ancestral position in relation to the phyletic lineages Hyphaereon and Oxycentrus sensu Noonan [1985b], and, in my opinion, does not differ morphologically from the American genus Selenophorus Dejean, 1829 which is ancestral group for many American genera. 
Some notes on Coleolissus and related genera

\section{Coleolissus Bates, 1892}

Coleolissus Bates, 1892: 338. Type species: Hypolithus perlucens Bates, 1878, designated by Andrewes [1939].

Tenuistilus Habu, 1978: 51. Type species: Tenuistilus teradai Habu, 1978, by original designation, syn.n.

Coleolissus was erected as a subgenus of Hypolithus Dejean, 1829 (= Hyparpalus Alluaud, 1930) for four species from Burma and one species (designated later as type species) from Kashmir [Bates, 1892], distinguished all from other congeners mainly by glabrous body and elytra with row of setigerous pores only on interval 3. More recently, Andrewes [1924] treated Coleolissus as a separate genus but he did not provide any additional characteristics of this taxon. Most of the subsequent authors also only described new species in this genus. According to Darlington [1968], the genus Coleolissus differs from $H y-$ phaereon in having last abdominal sternite with two pairs of marginal setae in both sexes and elytra with sutural angle denticulate, however he noted that these characteristics are based on New Guinean species only. Habu [1973], based on one species from southern Japan, three species from Indonesia and one from northern Australia, also considered Coleolissus as a separate genus having: elytra spinous at apex; scutellar striole developed; interval 3 with series of several small setigerous pores adjoining stria 2 (subgenus Coleolissus s. str.) or without pores (subgenus Neolissus Landin, 1955), and intervals 5 and 7 without series of pores. In addition, some later Habu [1978: 52] erected the genus Tenuistilus for one species from Taiwan as "allied to Coleolissus but it is distinguishable from it by the elytra never spinous at the apex and the unusually slenderer apical segment of the styluses, with the foramen close to the apex instead of being at the subapical area ....". Ito [1987: 21] mostly followed Habu's [1973, 1978] treatment but considered Tenuistilus as a subgenus of Coleolissus additionally to Neolissus and Coleolissus s. str. since styluses in Tenuistilus are "structurally similar to those of Coleolissus". The mentioned authors apparently never saw the type species of Neolissus and Coleolissus. Their examination revealed that the former taxon is conspecific with the genus Loxoncus Schmidt-Göbel, 1846 (subtribe Stenolophina) [Kataev, 2003] and the latter one corresponds to Tenuistilus sensu Ito, 1987. The examined holotype of C. perlucens at MNHN (female labeled "Jhelum Vall., Cashmere", "Hypolithus perlucens Bates" [Bates' handwriting] and "Ex Musaeo H.W. Bates, 1892") has elytra blunted at apex, not denticulate or spinous, and the gonocoxite (apical stylomere) curved and with seta on inner side situated preapically. According to the available data, the denticulate apex of elytron is a characteristic of most species of Coleolissus distributed in the Indo-Malay Archipelago, New Guinean region to northern Australia, and also in the Ryukyu Islands, Taiwan and Philippines, and does not occur in species from mainland Asia. In other characters, the species with denticulate elytral apex (= Coleolissus sensu Darlington, 1968 , Habu, 1973 and Ito, 1987) are very similar to the species with elytra not denticulate at apex although may represent one or more natural groups [Ito, 2017] warranting separate subgeneric status. It is worth noting, however, that gonocoxites of many species with denticulate elytral apex are elongate, weakly curved, with narrow base and with seta on inner side in apical position as described by Habu [1978] for Tenuistilus. Thus, Tenuistilus should be treated as synonym of Coleolissus.

Hyphaereon MacLeay, 1825

Hyphaereon MacLeay, 1825: 22. Type species: Harpalus (Hyphaereon) reflexus MacLeay, 1825, by monotypy.

Hyphaereon was originally described as a subgenus of Harpalus Latreille, 1802 for one species from Java, but already
Hope [1838] and Lacordaire [1854] considered it as a separate genus. In the former interpretation [Darlington, 1968], it was separated from Coleolissus by having abdominal sternite VII of male emarginated at apex, with one pair of setae in both sexes (outer pair of setae lacking), and elytra not denticulate at apex. Since these characters are variable in both Hyphaereon and Coleolissus, Noonan [1985a] considered these taxa as synonyms. According to my data, in Hyphaereon, the apical emargination of the abdominal sternite VII of male varies from somewhat deep (triangular or arcuate) to very weak, almost indistinct as, for example, in $H$. platynoides Ito, 2008; the number of setae on this sternite varies in both sexes from one pair to two pairs (in Coleolissus, the apex of last abdominal sternite in male is rounded or truncate, in some species emarginated; most species have two pairs of setae in both sexes, but some species have only one pair of setae in male). However, Hyphaereon differs from Coleolissus in very characteristic male genitalia: its median lobe is long and narrow, with very small basal bulb, and parameres are also very small, much smaller than those in Coleolissus. As compared with Coleolissus, many species of Hyphaereon have also smaller and more elongate body and pronotum with well-marked basal angles (in most Coleolissus, basal angles more or less widely rounded), although some species seems to be indistinguishable from Coleolissus based only on external characters. In my opinion, the aedeagus of Hyphaereon masumotoi (Ito, 1991) (not to be confused with Coleolissus masumotoi Ito, 1991) is somewhat intermediate in shape between aedeagi of Coleolissus and Hyphaereon. Since the modified aedeagus of Hyphaereon is apparently an apomorphic feature, it is most likely that this taxon represents a derivate lineage of Coleolissus. If this assumption is true, it would probably be more correct to regard Coleolissus as a subgenus of Hyphaereon.

\section{Calathomimus Bates, 1886}

Calathomimus Bates, 1886: 77. Type species: Calathomimus maculatus Bates, 1886, designated by Andrewes [1939].

The genus Calathomimus was erected for two species from Sri Lanka [Bates, 1886] with very characteristic setation of dorsum. Noonan [1976, 1985a] considered this taxon as congeneric with Hyphaereon since, according to this author and Darlington [1968], it differs from the latter only in having strongly angulate humeri and elytral intervals 7 carinate basally, the characters variable among members of $\mathrm{Hy}$ phaereon sensu Noonan [1985a]. In my opinion, such interpretation is incorrect and Calathomimus cannot be a synonym of Hyphaereon because differences between these taxa are very distinct. Based on the original description and examination of the type specimen (? holotype) of Calathomimus maculatus at MNHN (female labeled "Ceylon" and "Calathomimus maculatus Bates" [Bates' handwriting]), the genus Calathomimus is characterized by the following combination of distinctive characters: mandibles elongate; fronto-ocular furrows indistinct or very short, mentum with acute median tooth; pronotum with coarse setigerous punctation on disc and with several marginal setae; elytra with rows of setigerous pores on intervals 3,5 and 7; wings highly reduced; and metepisternum wider than long. In addition to the two species included originally, this genus also comprises $C$. hornianus Schauberger, 1938 also described from Sri Lanka, which has elytra with rows of coarse and sparse setigerous punctation on all intervals. Other species described as Calathomimus, including those described by Andrewes [1926, 1937], should be transferred to other genera. The genus Calathomimus, which seems to be an early derivative of the Oxycentrus phyletic stock sensu Noonan [1985b], may be related to the 
genus Oesyperus Andrewes, 1923 with three species from South India [Kataev, 2006], however, their true relationships requires special study and are still obscure. Like members of Calathomimus, all three species of Oesyperus are apterous, with transverse metepisterna, but well distinguished from them by having dorsum almost throughout (except for eyes, labrum and mandibles) covered with short erect setae, and head with fronto-ocular furrows reaching deep supraorbital furrows, which are more or less straight and prolonged to neck constriction behind eyes. Two these genera seem to be relicts of the ancient Indian fauna preserved in South India and Sri Lanka.

\section{Allosiopelus Ito, 1995}

Allosiopelus Ito, 1995: 153. Type species: Allosiopelus punctatipennis Ito, 1995, by original designation.

This genus was erected for one species from South India. As stated in the original description [Ito, 1995: 154], this genus is closely related to Calathominus based on "the elongate mandibles and the elytra glabrous on the dorsal surface and protruded at the humeral angles ... but it is differing from it in having the elytra coarsely and densely punctate and with row of setigerous pores on $5^{\text {th }}$ interval, and the ventral surface more densely pubescent". More recently, Ito [2016] described new species A. fulvicollis Ito, 2016, also from South India, differing from the type species (among other distinctive characters) in elytra much less sparsely punctate and abdominal sternites almost glabrous. The status of Allosiopelus needs further study because punctation of elytral intervals and pubescence of abdominal sternites are highly variable within Coleolissus; for example, elytra are rather coarsely and densely punctate in $C$. iris Andrewes, 1924, and abdominal sternites are throughout covering with fine short setae in C.perlucens, the type species of Coleolissus. Besides, I examined one species, apparently still undescribed, also from South India, which in all characters, including the male genitalia, is very similar to A. punctatipennis but with row of setigerous pores present only on interval 3 . It is very possible that Allosiopelus should be included in Coleolissus. For example, the genus Siopelus comprises species both with and without rows of setigerous pores on elytral intervals 5 and 7 .

Acknowledgements. I am very grateful to Thierry Deuve and Azadeh Taghavian (MNHN) for loan of the type specimens from the collections under their care, and to Sergey V. Saluk (Minsk, Belarus) for donation of very interesting material of Harpalini from India, including this new species.

The study was performed within the frame of State project no. AAAA-Â19-119020690101-6 and supported by the Russian Foundation for Basic Research (grant no. 19-04-00565).

\section{References}

Andrewes H.E. 1924. Description on some new Carabidae from Ceylon (part II) // Spolia Zeylanica. Vol.13. Pt.1. P.129-141.

Andrewes H.E. 1926. Papers on Oriental Carabidae. - XVI // Ann. Mag. Nat. Hist. Ser.9. Vol.17. No.13. P.252-259. https://doi.org/ 10.1080/00222932608633402.

Andrewes H.E. 1937. On some new species of Carabidae, chiefly from Java (III) // Treubia. Vol.16. P.25-35.

Andrewes H.E. 1939. XIV. - Papers on Oriental Carabidae.- XXXV // Ann. Mag. Nat. Hist. Ser.11. Vol.3. No.13. P.128-139. https:// doi.org/10.1080/03745481.1939.9723582.

Baehr M. 2018. Three new species of the genus Coleolissus Bates from New Guinea (Coleoptera, Carabidae, Harpalini) // Entomofauna. Bd.39/1. H.2. S.45-58.
Bates H.W. 1886. On the geodephagous Coleoptera collected by Mr. George Lewis in Ceylon// Ann. Mag. Nat. Hist. Ser.5. Vol.17. P.68-212, 214-221. https://doi.org/10.1080/00222938609460134.

Bates H.W. 1892. Viaggio di Leonardo Fea in Birmania e regioni vicine. XLIV. List of the Carabidae //Ann. Mus. Stor. Nat. Genova. Vol.32. P.267-428.

Darlington P.J., Jr. 1968. The carabid beetles of New Guinea. Part. III. Harpalinae (continued): Perigonini to Pseudomorphini // Bull. Mus. Comp. Zool. Vol.137. No.1. P.1-253.

Ito N. 1987. Three new species of the genus Coleolissus (Harpalini) from Southeast Asia, with the subgeneric note (Coleoptera, Carabidae) // Ent. Rev. Japan. Suppl. Vol.42. P. 21-29.

Ito N. 1990. Study on Asian Carabidae, I. (Coleoptera) // Ent. Rev. Japan. Vol.45. No.2. P.81-86.

Ito N. 1991a. Study on Asian Carabidae II. Carabidae // Ent. Rev. Japan. Vol.46. No.1. P.21-26.

Ito N. 1991b. Study on Asian Carabidae III. Carabidae // Ent. Rev. Japan. Vol.46. No. 2. P.157-169.

Ito N. 1993. Study on Asian Carabidae, V (Coleoptera). The species of the genus Coleolissus Bates // Ent. Rev. Japan. Vol.48. No.1. P.47-56.

Ito N. 1995. Two new species of harpaline beetles (Coleoptera) from Southeast Asia // Spec. Bull. Jpn. Soc. Coleopterol. Vol.4. P.267273.

Ito N. 1995. A new genus and two new species of the Selenophori group (Harpalini, Carabidae, Coleoptera) // Jpn. J. syst. Ent. Vol.1. No.2. P.153-159.

Ito N. 1997a. Two new species of the Selenophori group (Coleoptera, Carabidae, Harpalini) from Asia // Elytra. Vol.25. P.515-520.

Ito N. 1997b. Two new species of the genus Oxycentrus from Vietnam (Coleoptera, Carabidae, Harpalini) // Ent. Rev. Japan. Vol.52. No.1. P.39-43.

Ito N. 1999. A new species of the genus Coleolissus from Laos (Coleoptera: Carabidae: Harpalini) // Ent. Rev. Japan. Vol.54. No.2. P.165-168

Ito N. 2001. A first record of harpaline genus Coleolissus from the Philippines with descriptions (Coleoptera: Carabidae) // Ent. Rev. Japan. Vol.56. No.1. P.25-30.

Ito N. 2004. Descriptions of four new species of the Selenophori group (Harpalini: Carabidae) from Asia, including first record of the genera of Coleolissus and Hyphaereon from Laos. (Coleoptera) // Ent. Rev. Japan. Vol.59. No.2. P.275-286.

Ito N. 2006. Three new species of the harpaline Selenophori group from Asia (Coleoptera, Carabidae) // Elytra. Vol.34. No.2. P.267-274.

Ito N. 2007. Two new species of the harpaline Selenophori group (Coleoptera, Carabidae) from North Vietnam // Elytra. Vol.35. No.1. P.27-33.

Ito N. 2008. Species of the harpaline Selenophori group (Coleoptera: Carabidae) from Asia // Taichius, Spec. Publ. Jpn. Soc. Coleopterol. Vol.2. P.39-81.

Ito N. 2014. New taxa of the Harpaline Selenophori group from Tropic Asia (Coleoptera: Carabidae: Harpalinae) // Jpn. J. syst. Ent. Vol.20. No.1. P. 61-80.

Ito N. 2016. Six new species of the Selenophori carabids from India and adjacent regions (Coleoptera, Carabidae, Hatrpalini) // Elytra. N.S. Vol.6. No.2. P.359-372.

Ito N. 2017. Five new species of the Selenophori genus group from Tropical Asia (Coleoptera, Carabidae, Harpalini) // Spec. Bull. Jpn. Soc. Coleopterol. Vol.1. P.49-60.

Ito N., Liang H. 2018. Four new species of the Selenophori genus group from Asia. (Coleoptera, Carabidae, Harpalini) // Bull. Osaka Mus. Nat. Hist. No.72. P.33-41.

Ito N., Wrase D.W. 1998. A new brachypterous species of the genus Coleolissus from Yunnan (Coleoptera; Carabidae; Harpalini) // Ent. Rev. Japan. Vol.53. P.43-46.

Habu A. 1973. Fauna Japonica. Carabidae: Harpalini (Insecta, Coleoptera). Tokyo: Keigaku Publishing Co. xiii +430 pp.

Habu A. 1978. Tenuistilus teradai gen. nov. and sp. nov. from Formosa (Coleoptera, Carabidae, Harpalini) // Proc. Jpn. Soc. Syst. Zool. Vol.15. P.51-55.

Hope F.W. 1838. The coleopterist's manual, part the second, containing the predaceous land and water beetles of Linneus and Fabricius. London: H.G. Bohn xvi +168 pp. + [1]. 4 pls. 
Kataev B.M. 2003. Revision of the genus Loxoncus Schmidt-Göbel, 1846 from the Palaearctic, the Oriental Region and Australia (Coleoptera: Carabidae: Harpalini) // Rus. Entomol. J. Vol.11. No.4. 2002. P.351-382.

Kataev B.M. 2006. A taxonomic review of the genus Oesyperus (Coleoptera: Carabidae: Harpalini) // Zootaxa. Vol.1286. P.43-55.

Kataev B.M., Wrase D.W., Ito N. 2003. Harpalina // Löbl L., Smetana A (eds.). Catalogue of Palaearctic Coleoptera. Volume 1. ArchostemataMyxophaga - Adephaga. Stenstrup: Apollo Books. P.367-397.

Lacordaire J.T. 1854. Histoire naturelle des insectes. Genera des coléoptères ou exposé méthodique et critique de tous les genres proposés jusqu'ici dans cet ordre d'insectes. Tome premier contenant les familles des cicindélites, carabiques, dytiscides, gyrinides, et palpicornes. Paris: Roret. xx +486 pp. https://doi.org/ 10.5962/bhl.title. 8864 .

Macleay W.S. 1825. Number 1. of Annulosa Javanica, or an attempt to illustrate the natural affinities and analogies of the insects collected in Java by Thomas Horsfield, M.D. F.L. \& G.S. and deposited by him in the museum of the honourable East-India Company. London: Kingsbury, Parbury \& Allen. P.I-XII, 1-50, Pl.1. https://doi.org/10.5962/t.172997.

Noonan G.R.1976. Synopsis of the supra-specific taxa of the tribe Harpalini (Coleoptera: Carabidae) // Quaest. Entomol. Vol.12. P.3-87.

Noonan G.R. 1985a. Classification and names of the Selenophori group (Coleoptera: Carabidae: Harpalini) and of nine genera and subgenera placed in incertae sedis within Harpalina // Milwaukee Public Museum, Contributions in Biology and Geology. No.64. P.1-92.

Noonan G.R. 1985b. Reconstructed phylogeny and zoogeography of the genera and subgenera of the Selenophori group (Insecta: Coleoptera: Carabidae: Harpalini: Harpalina) // Milwaukee Public Museum, Contributions in Biology and Geology. No.65. P.1-33. 